\title{
Flavoenzyme-Catalyzed Electrochemical Oxidation of NADH and NADPH in the Absence of External Mediators
}

\author{
Daisuke KOBAYASHI, Shogo OzAWA, Tatsuya MiHARA ${ }^{\dagger}$ and Tokuji IKEDA*
}

\author{
Received June 15, 1992 ; Accepted August 24, 1992
}

\begin{abstract}
Diaphorase from Bacillus stearothermophilus (EC 1.1.99-) was entrapped on the surfaces of carbon paste and glassy carbon electrodes by covering with dialysis membranes. Ferredoxin- $\mathrm{NADP}^{+}$reductase $(\mathrm{EC} 1.18 .1 .2)$ was adsorbed on the surfaces of glassy carbon, gold and silver electrodes by a dip coating method. Both electrodes modified with these enzymes produced anodic currents due to the enzyme-catalyzed electrolytic oxidation of their substrates in the absence of both electron transfer mediators and promoters. The electrocatalysis behavior was analyzed by an equation for the electrocatalytic oxidation of a substrate at the electrode modified with an adsorbed enzyme, using the electrode as an electron acceptor.
\end{abstract}

\section{Introduction}

In recent years increasing attention has been paid to the electrocatalysis based on oxidoreductases, bioelectrocatalysis, and to the enzyme electrodes relying upon bioelectrocatalysis. ${ }^{1)}$ To achieve the enzyme-electrochemical oxidation of the substrates, redox compounds serving as electron transfer mediators between the oxidoreductases and the electrodes have usually been employed because of sluggish electrode reactions of oxidoreductases. 1,2) More recently, however, bioelectrocatalysis based on direct electron transfer of oxidoreductases at electrodes have been realized with several kinds of oxidoreductases in the presence of

Department of Agricultural Chemistry, Faculty of Agriculture, Kyoto University, Sakyo-ku, Kyoto 606

${ }^{+}$Present address: Research and Development. Center, Unitika Ltd. Kyoto.

Key words: Bioelectrocatalysis, diaphorase, FNR. promotors such as aminoglycosides ${ }^{3,4)}$ and even in the absence of promotors. $4 c^{-8}$ ) Interestingly, all of the oxidoreductases employed contain heme gropus and/or $\mathrm{Fe}-\mathrm{S}$ clusters, which are also contained in electrochemically active redox proteins such as cytochromes $\mathrm{c}$ and ferredoxins. We have interested in the oxidoreductases contatining only flavins as redox groups. We employ here diaphorase and ferredoxin$\mathrm{NADP}^{+}$reductase, FNR, both of which can be obtained in highly purified states. The electrocatalysis behavior of the electrodes modified with these enzymes have been studied in the absence of external mediators.

\section{Experimental}

Diaphorase (EC 1.6.99.-, from Bacillus stearothermophilus; molecular weight ca. 30000 , one falvine mononucleotide, FMN, per molecule) ${ }^{9)}$ was donated from Unitika Ltd. The purity of the lyophilized preparation was checked by SDSpolyacrylamide gel electrophoresis. FNR, (EC 1.18.1.2, from spinach leaves, molecular weight 35000 , one flavine 
adenine dinucleotide, FAD, per molecule) was donated from Prof. Asada as crystalline suspension in ammonium

sulfate. 10) The FNR suspension was dialyzed against $50 \mathrm{mM}$ Tris-HCl buffer of $\mathrm{pH} 7.5$ before use, and the concentration of FNR was determined spectrophotometrically using the absorption coefficient of $10300 \mathrm{M}^{-1} \mathrm{~cm}^{-1}$ at $458 \mathrm{~nm} .10$ )

Carbon paste electrodes (CPE, geometrical surface area: $0.09 \mathrm{~cm}^{2}$ ) were prepared as described previously. 11) A glassy carbon electrode (GCE, $3 \mathrm{~mm}$ diameter) and a gold electrode (AuE, 1.6 $\mathrm{mm}$ diameter) were obtained from BAS Corp. A disk of silver (2 mm diameter) sealded to the end of glass tubing with epoxy cement was used as a silver electrode $(A g E)$. The GCE, AuF, and AgE were polished to a mirror-ljke finish with $0.05 \mu \mathrm{m}$ alumina, followed by rinsing with deionized water in a ultrasonic bath. Film-covered enzyme-entrapped electrodes were prepared according to the method described previously. 11) Thus the enzvmes were entrapped on the electrode surfaces by covering with dialysis membranes. Electrodes with adsorbed enzyme were prepared by dipping the electrodes in an enzyme solution for a given period of time, followed by rinsing with deionized water.

Electrochemical measurements were done at $25^{\circ} \mathrm{C}$ in a buffer solution deaerated with argon. The solution was stirred at the rate of $400 \mathrm{rpm}$ with a magnetic stirrer, unless stated otherwise. At this stirring rate, the concentration polarization of the substrates in solution was negligibly small. Three electrode system was employed; an $\mathrm{Ag} / \mathrm{AgCl}$ (saturated $\mathrm{KCl}$ ) electrode and a platinum coil as a reference electrode and a couter electrode, respectively.

\section{Results and Discussion}

\subsection{Diaphorase}

Figure 1 shows cyclic voltammograms in pH 8.5 Tris buffer solution recorded with

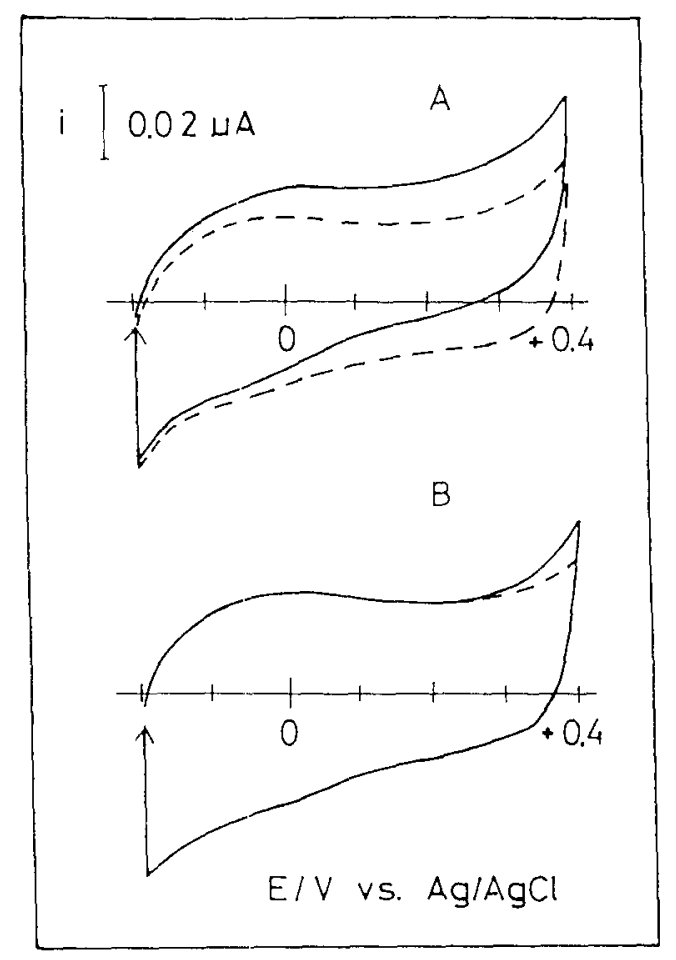

Fig. 1 Cyclic voltamograms of (A) a filmDiaph-CPE and (B) a bare CPE with a dialysis membrane in $\mathrm{pH} 8.5$ Tris buffer in the absence (broken lines) and presence of $65 \mu \mathrm{M}$ NADH solid lines). Scan rate 10 $\mathrm{mV} / \mathrm{s}$.

(A) a dialysis membrane-covered diaphorase (1.1 $\left.\mathrm{\mu g} / \mathrm{cm}^{2}\right)$-entrapped CPE, a film-Diaph $\left(1.1 \mu \mathrm{g} / \mathrm{cm}^{2}\right)-C P E$, and with (B) a bare CPE with a dialysis membrane. In the presence of $65 \mu \mathrm{mol} / \mathrm{dm}^{3}$ ( $\left.\mu \mathrm{M}\right) \mathrm{NADH}$, an anodic current started to appear at $-0.2 \mathrm{~V}$ at the film-Diaph-CPE, (Fig.1A), whereas at the potential more positive than $0.35 \mathrm{~V}$ at the bare CPE with a dialysis membrane (Fig.1B). When the current was measured with the film-Diaph-CPE at a fixed electrode potential, a steady-state current, I, was obtained. I increased with increasing concentration of NADH to approach a saturation value as shown in Fig. 2, which was obtained with film-Diaph (11 $\mu \mathrm{g} / \mathrm{cm}^{2}$ )-CPEs at $0 \mathrm{~V}$. The results indicate that the steady-state current is due to the diaphorase-catalyzed 


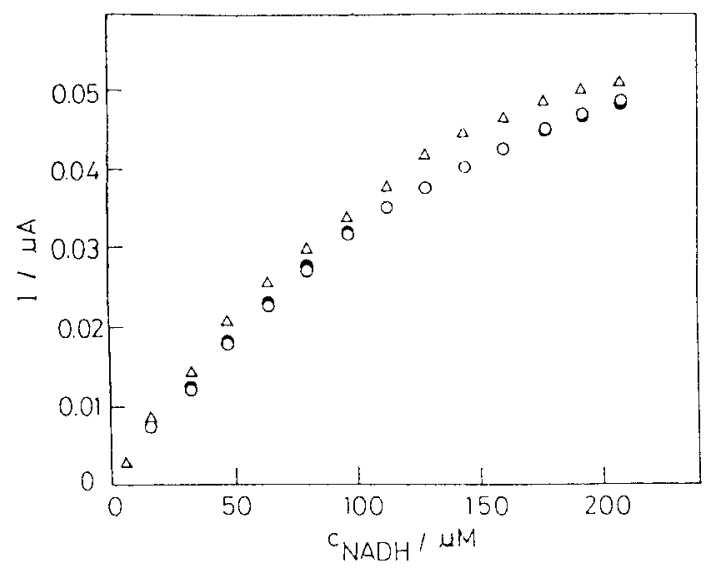

Fig. 2 Dependence of the steady-state current, $\mathrm{I}$, at $0 \mathrm{~V}$ vs. $\mathrm{Ag} / \mathrm{AgCl}$ on the concentration of $\mathrm{NADH}, \mathrm{C}_{\mathrm{NACH}} \cdot \mathrm{O}, \mathrm{O}$, and $\triangle$ are the data measured with three different film-Diaph-CPEs prepared by the same procedure.

electrochemical oxidation of $\mathrm{NADH}$. I measured at $0 \mathrm{~V}$ and at $100 \mu \mathrm{M}$ NADH was independent of $\mathrm{pH}$ of the solution in the range from 7.5 to 10.5 , and $I$ at $\mathrm{pH} 10.5$ increased with the increase in temperature from 25 to $50^{\circ} \mathrm{C}$; the Arrhenius activation energy was determined to be $46 \mathrm{~kJ} / \mathrm{mol}$ from the temperature dependence. These results are in line with the fact that the diaphorase employed here is thermostable and stable in alkaline solution. 9a) We have added neither mediatons nor promoters to the solution in the electrochemical measurements. Therefore, the direct electron transfer reaction of the enzyme at the electrode is necessary for the enzyme-catalyzed electrochemical oxidation. It should be noted, however, that diaphorase employed in this study can use FN as an electron acceptor to mediate the electron transfer reaction between the enzyme reaction and the electrode reaction. 12 ) Therefore, a small amount of free FMN dissociated from the enzyme, if present in solution, may function as a mediaor to produce a catalytic current for the oxidation of NADH. We have shown that the catalytic current due to the mediation of FMN begins tc appear at -0.5
$V$ with a mid potential of $-0.47 \mathrm{~V}$, the potential at the half height of the limiting current. ${ }^{12)}$ Figure 3 shows the dependence of the steady-state current on the potential obtained with a filmDiaph $\left(22 \mu \mathrm{g} / \mathrm{cm}^{2}\right)-\mathrm{CPE}$. The current starts to appear at $-0.2 \mathrm{~V}$ and the mid potential is $-0.07 \mathrm{~V}$. This is evidently different from the potential dependence of the current due to the FMN-mediated electrocatalysis. The results support the idea that the direct electron transfer of diaphorase is occuring at the diaphorasemodified electrode during the electrocatalysis, though the wave clearly attributable to the redox reaction of the active site of the erizyme is not observed in the present experimental conditions. When GCE was used in place of CPE, the film-Diaph-GCE also produced the catlytic current, and the potential dependence of the steady-state current was very similar to that obtained with the film-Diaph-CPE (Fig. 3). However when AuE was used, the film-Diaph-AuE showed no detectable current responce to $\mathrm{NADH}$. The electrode reaction of diaphorase may be sluggish at a gold electrode.

The dependence of the steady-state

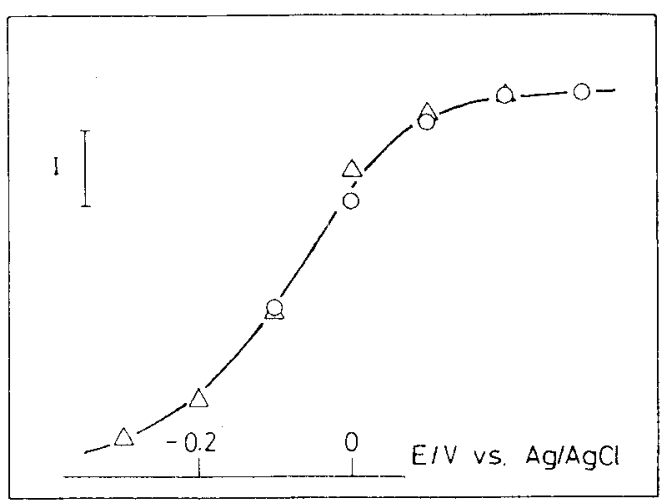

Fig. 3 Dependence of the steady-state current on the electrode potential. The steady-state currents were measured (0) with film-Diaph $\left(22 \mu \mathrm{g} / \mathrm{cm}^{2}\right)-\mathrm{CPE}$ and $(\Delta)$ with film-Diaph $\left(22 \mu \mathrm{g} / \mathrm{cm}^{2}\right)-\mathrm{GCE}$ in $\mathrm{pH}$ 8.5 Tris buffer containing $82 \mu \mathrm{M}$ NADH. I: $\bigcirc 0.11 \mu \mathrm{A} / \mathrm{cm}^{2}$, and $\Delta 0.055 \mu \mathrm{A} / \mathrm{cm}^{2}$. 


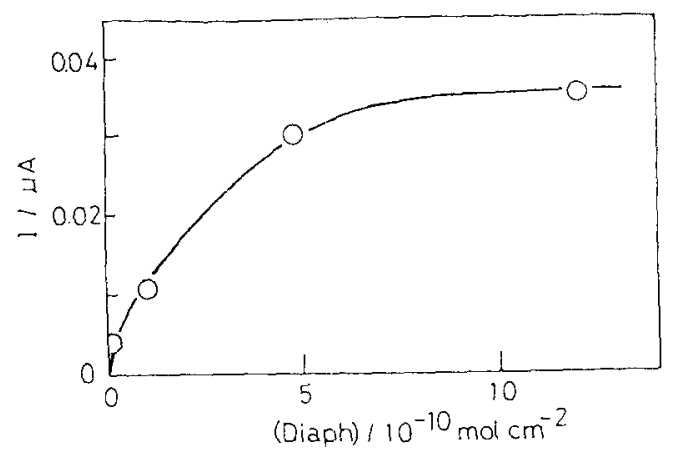

Fig. 4 Dependence of the steady-state current at $0 \mathrm{~V}$ on the amourt of entrapped diaphorase, (Diaph). The concentration of NADH is $82 \mathrm{uM}$.

current on the amount of entrapped diaphorase of film-Diaph-CPE is shown in Fig. 4. The current increased with the increase in the amount of entrapped enzyme to approach a saturation value. The step determining the magnitude of the saturation current should be the process of the permeation of $\mathrm{NADH}$ into the dialysis membrane covering the enzyme layer or the process of the enzymatic reaction. If we assurne that the permeation process is the limiting step, we can calculate the limiting current to be 0.49 $\mu A$ from an equation, $I=\operatorname{rFA}\left(\mathrm{D}_{\mathrm{m}} / \mathrm{d}\right)(\mathrm{NADH})$, where $n, F, A$ are the number of electrons, the Faraday constant, and the electrode surface area, respectively; $D_{m}$ is the diffusion coefficient of NADH in the membrane, d the thickness of the membrane, and (NADH) the concentration of NADH at the surface of the memebrane layer in the solution, which can be equated to the bulk concentration of $\mathrm{NADH}$, since the concentration polarization of $\mathrm{NADH}$ is negligibly small in the present experimental conditions. In the calculation, the $D_{m}$ and $d$ values of $1 \times 10^{-6}$ $\mathrm{cm}^{2} / \mathrm{s}$ and $30 \mu \mathrm{m}$, respectively, were used. 13) The calculated value of $0.49 \mu \mathrm{A}$ is about ten fold large compared with the saturation value in Fig. 4. Therefore, the saturation tendency should be ascribed to arother process, the process of the enzymatic reaction.
When an adsorbed enzyme is taking part in the enzymatic reaction as written by

$\mathrm{S}+[\text { Eox }]_{\mathrm{ad}} \underset{\mathrm{k}_{-1}}{\stackrel{\mathrm{k}_{1}}{\rightleftharpoons}}[\mathrm{ES}]_{\mathrm{ad}} \stackrel{\mathrm{k}_{2}}{\longrightarrow}[\text { Ered }]_{\mathrm{ad}}+\mathrm{P}$

and

$$
[\text { Ered }]_{\text {ad }} \longrightarrow[\text { electrode }] \text { ad }
$$

an equation for the steady-state limiting current is given by ${ }^{14}$ )

$$
I=I_{\max }(S) /\left(K_{m}+(S)\right)
$$

with

$$
I_{\max }=n \operatorname{nFAk}_{2}(E)_{\mathrm{ad}}
$$

Where [Eox $]_{\text {ad }},[\text { Ered }]_{\text {ad, }}$ and $[\mathrm{ES}]_{\text {ad }}$ are the adsorbed enzyme in the states of oxidized and reduced forms and an enzymesubstrate complex, respectively; $\mathrm{S}$ and $\mathrm{P}$ the substrate and product, respectively; $k_{1}, k_{-1}$, and $k_{2}$ the rate constants of the steps in eq. 1; (S) the concentration of the substrate at the electrode surface, and $K_{m}$ and $(E)_{a d}$ the Michaelis constant of the enzyme reaction, eq. 1 , and the total concentration of the adsorbed enzyme, respectively.

An alternative to the above scheme of the enzymatic reaction is that the solubilized enzyme in the vicinity of the electrode surface takes part in the enzyme-electrochemical reaction. In this case, [EOx $]_{a d},[\text { Ered }]_{\text {ad, }}$, and [ES $]_{a d}$ in eqs. 1 and 2 should be replaced by the respective states of the enzyme in solution, and an expression for the steady-state liniting current is given by

$$
\begin{aligned}
I & =I_{\text {max }}\left((S) /\left(K_{m}+(S)\right)^{1 / 2}\right. \\
\text { with } & \\
I_{\text {max }} & =\operatorname{nFA}\left(D k_{2 b}\right)^{1 / 2}(E)
\end{aligned}
$$

where $D$ and (E), respectively, are the diffusion coefficient and the concentration of the enzyme; $k_{2 b}$ is the rate constant of the enzyme reaction in solution.

Equations 5 and 6 predict that I 
increases linearly with (E), which is not consistent with the nonlinear dependence of $I$ on the concentration of entrapped enzyme in Fig. 4. Equations 3 and 4 show that I depends on $(E)_{a d}$, that is, a quantity nonlinearly related to $(E)$. Thus eqs. 3 and 4 may explain the results in Fig. 4. The adsorbability of diaphorase was examined by a dip coating method. A CPE was dipped into a diaphorase solution for $60 \mathrm{~s}$, then the electrode was rinsed with water. The $\mathrm{CPE}$ treated with the diaphorase solution showed current response to the addition of $\mathrm{NADH}$ when measured at $0 \mathrm{~V}$ in a pH 8.5 buffer solution, but the current nagnitude tended to decrease during continuous measurements of the current for $10 \mathrm{~min}$, indicating that the adsorbability of CPE to the enzyme is weak. Accordingly, an explanation of the result in Fig. 4 is that there exists an adsorption equilibrium between the adsorbed enzyme and the enzyme in soltion, and that the maximum adsorption is attained at the concentration, $5 \times 10^{-10}$ $\mathrm{mol} / \mathrm{cm}^{2}$, of entrapped diaphorase. This quantity can be converted to the bulk concentration of $0.5 \mathrm{mM}$, if the thickness of the layer of the entrapped enzyme between the electrode and the dialysis membrane is assumed to be $1 \mu \mathrm{m}$. The adsorbability of GCE was even weaker than CPE when examined in the same manner as CPE.

Although we are unable to measure the amount of the adsorbed diaphorase on CPE, we can analyze the dependence of $I$ on the concentration of $\mathrm{NADH}, \mathrm{c}_{\mathrm{NADH}}$, (Fig. 2) by eq. 3. The plot of $\mathrm{c}_{\mathrm{NADH}} / \mathrm{I}$ against $\mathrm{c}_{\mathrm{NADH}}$ of the data in Fig. 2 gave linear lines as expected from eq. 3 , from which the $I_{\max } / A$ and $\mathrm{K}_{\mathrm{m}}$ values were determined to be $1.0 \pm 0.2 \mu \mathrm{A} / \mathrm{cm}^{2}$ and $0.17 \pm 0.02 \mathrm{mM}$, respectively. The $K_{m}$ value agrees broadly with results from the measurements in solution using artificial dyes as electron acceptors. $9 a)$ If we use the $k_{2 b}$ value, 500 $\mathrm{s}^{-1}$, calculated from the specific activity of the enzyme, $9 a$ ) we can calculate from eq. 4 with the $I_{\max }$ value the amount of adsorbed enzyme as $1 \times 10^{-14} \mathrm{~mol} / \mathrm{cm}^{2}$. This is too small compared with the monomolecular surface coverage, $4 \times 10^{-12}$ $\mathrm{mol} / \mathrm{cm}^{2}$ of the molecules with the molecular weight ca. $\left.30000 .{ }^{15}\right)$ The $k_{2}$ value of the adsorbed diaphorase might be very small or only very small part of the adsorbed molecules might be catalytically active.

\subsection{FNR}

FNR were adsorbed more strongly than diaphorase on a number of electrode materials. Thus, a gold electrode was dipped into an FNR solution for $60 \mathrm{~s}$, then rinsed with water. The AuE with the adsorbed FNR, FNR-AuE, was immersed in a pH 7.5 Tris buffer solution, and the current response to NADPH was recorded at a fixed electrode potential. Figure 5 shows the results measured with the FNR$\mathrm{AuE}$ at $\mathrm{OV}$. As shown in the inset, an anodic current was otained by the addition of NADPH, and a steady-state current was attained in seconds. The current magnitude remained almost constant during the continucus measurements for more than $30 \mathrm{~min}$, inclicating that FNR was

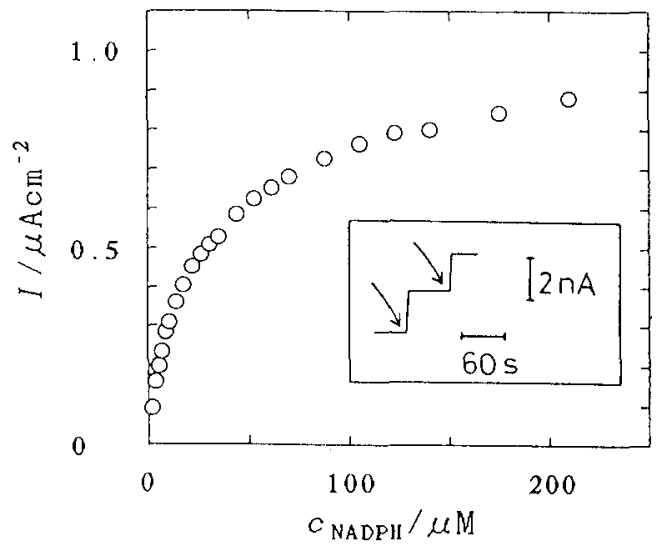

Fig. 5 Dependence of the steady-state current on the concentration of NADPH. The steady-state currents were measured at $0 \mathrm{~V}$ in $\mathrm{pH} 7.5$ Tris buffer solution with an FNR-adsorbed AuE. The inset shows the current response of the electrode to the addition (indicated by the arrows) of $2 \mu \mathrm{M}$ NADPH to the buffer solution. 


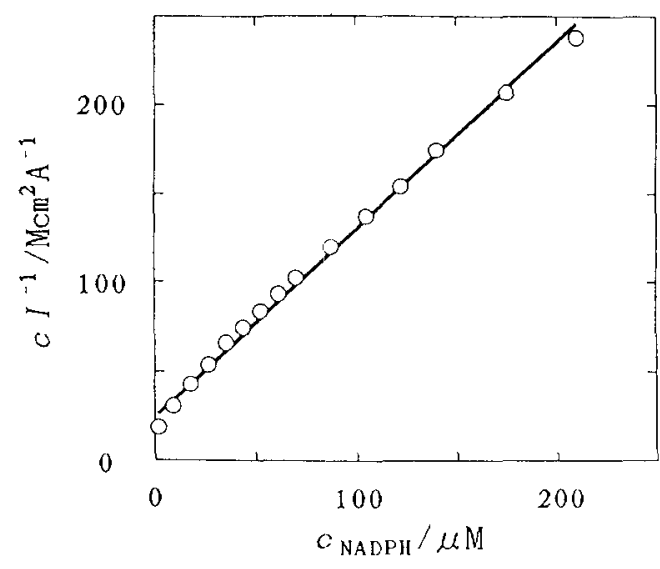

Fig. 6 Plot of $\mathrm{c}_{\mathrm{NADPH}} / \mathrm{I}$ against $\mathrm{c}_{\mathrm{NADPH}}$.

adsorbed on an AuE rather strongly. The steady-state current, I, increased with increasing concentration of NADPH, $\mathrm{c}_{\mathrm{NADPH}}$, to approach a saturation value. Figure 6 shows the plot of $\mathrm{c}_{\mathrm{NADPH}} / \mathrm{I}$ against $\mathrm{c}_{\mathrm{NADH}}$ of the data in Fig. 5. A linear relationship was obtained as expected from eq. 3 , and the $I_{\max } / A$ and $K_{m}$ values were determined from the slope and intercept. The anodic current response was also obtained at more negative potentials up to $-0.5 \mathrm{~V}$. FNR could also be adsorbed on GCE and AgE. The FNR-GCE and FNR-AgE prepared by the same method as the FNR-AuE produced anodic currents when NADPH was added to the solution. Similar dependences of $I$ on $\mathrm{c}_{\text {NADPH }}$ to that in Fig. 5 were obtained with these electrodes, from which the $I_{\max } / A$ and $K_{m}$ values could be calculated by using eq. 3 . The $I_{\max } / A$ values are $0.91 \pm 0.19,0.24 \pm 0.06$, and $0.86 \pm 0.48$ $\mu \mathrm{A} / \mathrm{cm}^{2}$, and the $\mathrm{K}_{\mathrm{m}}$ values are $22 \pm 1.8$, $17 \pm 2.1$, and $93 \pm 19 \mu \mathrm{M}$ for FNR-AuE, FNR-GCE, and FNR-AgE, respectively. Each data is the means of two measurements. There are differences in both the $I_{\max } / A$ and $K_{m}$ values obtained with the three kinds of electrodes, though these $K_{m}$ values are in the same order of magnitude as those reported for FNR reactions using several kinds of electron acceptors. ${ }^{16)}$ The results may indicate that small conformational changes of FNR occur by adsorption on electrode surfaces. The catalytic constsnt, $\mathrm{k}_{2}$, which is related to $I_{\max } / A$ by eq. 4 , and the affinity to the substrate, $\mathrm{K}_{\mathrm{m}}$, of the adsorbed enzyme should be sensitive to the conformational state of the enzyme adsorbed on electrodes. The amount of adsorbed enzyme, (E) ad, may also depend on the kind of electrodes on which the enzyme is adsorbed. If we use the $k_{2}$ value, $60 \mathrm{~s}^{-1}$, calculated from the specific activity of the native enziyme, ${ }^{10}$ ), we can calculate the amount of adsorbed enzyme from the $I_{\max } / A$ values 0.91 to $0.24 \mu \mathrm{A} / \mathrm{cm}^{2}$, by eq. 4 to be 7.8 to $2.1 \times 10^{-14} \mathrm{~mol} / \mathrm{cm}^{2}$. The actual anount of adsorbed enzyme will be more large, because the $k_{2}$ value will be smaller than $60 \mathrm{~s}^{-1}$ owing to the expected conformational change of the adsorbed enzyme. Although we tried to record the redox wave for the adsorbed FNR itself and the catalytic current for the reduction of $\mathrm{NADP}^{+}$, we were unable to obtaine the wave and the current clearly distingushiable from the base current under the present experimental conditions. In spite of this, the observation of the catalytic currents in the absence of mediators show the electron transfer reaction of the adsorbed FNR at the electrode, by which the enzymeelectrochamical oxidation of NADPH is allowed to occur. FNR has different sites to react with the cofactor and an acceptor (or donor). 17) Accordingly, if the adsorbed FNR is appropriately oriented with the reaction site for an acceptor toward the electrode surface, the electrocatalysis usig the electrode as an electron acceptor may become possible. The electrocatalysis observed with adsorbed diaphorase might be occuring in a similar way, though the three dimensional structure of the molecule is not yet known.

\section{Conclusion}

It has been shown that diaphorase and FNR catalyze the electrochemical oxidation of NADH and NADPH, respectively, in the absence of both elecron transfer mediators and promoters. The electrocatalytic behavior could be explained by an equation 
for the catalysis of an adsorbed enzyme, using the electrode as an electron acceptor. Diaphorase was adsorbed on CPE and GCE rather weakly; on the other hand, FNR was adsorbed more strongly on GCE, AuE and AgE.

T.I thanks to Professor Koji Asada, the Research Institute for Food Science, Kyoto University for donating purified FNR and to Unitika Ltd. for donating diaphorase.

\section{References}

1) M. Senda and T. Ikeda, in Bioinstrumentation: Research, Developments and Applications, ed. D.L.Weise, Butterworths, Boston, 1990, pp.189.

2) A. Heller, J. Phys. Chem., 96, 3579 (1992) and references therein.

3 ) F. A. Armstrong and A. M. lannon, J. Am. Chem. Soc., 109, 7211 (1987).

4) (a) L. H. Guo, H. A. O. Hill, G. A. Lawrence, G. S. Sanghera, and D. J. Hopper, J. Electroanal. Chem., 379 (1989), (b) L. H. Guo, H. A. O. Hill, D. J. Hopper, G. A. Lawrence, and G. S. Sanghera, J. Biol. Chenl., 265, 1958 (1990), (c) A. L. Burrows, H. A. O. Hill, T. A. Lees, W. S. McIntire, H. Nakayama, and G. S. Sanghera, Eur. J. Biochem., 199, 73 (1991).

5)(a) M. R. Tarasevich, A. I. Yaropolov, V. A. Bogdanovskaya, and S. D. Varfolmeev, Bioelectrochem. Bioenerg., 6, 393 (1979), (b) F. C. Anson, H. B. Gray, C. W. Lee, and B. G. Malmstrom, $J$. Electroanal .
Chem., 172, 289 (1984).

6) R. M. Paddock and E. F. Bowden, J. Electroanal. Chem., 260, 487 (1989).

7) (a) T. Ikeda, F. Fushimi, K. Miki, and M. Senda, Agric. Biol. chem., 52, 2655 (1988), (b) T. Ikeda, S. Miyaoka, F. Matsushita, D. Kobayashi, and M. Senda, Chem. Lett., 1992, 847.

8) A. Suckera, B. A. C. Ackrell, B. Cochran, and F. A. Armstrong, Nature, 356, 361 (1992).

9) (a) Catalogue of Unitika Enzymes, Unitika Ltd., Osaka, 1989, (b)T. Matsue, H. Yamada, H-C. Chang, I. Uchida, K. Nagata, and K. Tomita, Biochim. Biophys. Acta, 1038, 29 (1990).

10) K. Asada and M. Takahashi, Plant \& Cell Physiol., 12, 361 (1971).

11) T. Ikeda, H. Hamada, K. Miki, and M. Senda, Agric. Biol.. Chem., 49, 541 (1985).

12) S. Ozawa, T. Ikeda, and M. Senda, Anal. Sci., 7, 1689 (1991).

13) T. Ikeda, T.Shibata, and M. Senda, J. Electroanal. Chem., 261, 351 (1989).

14) S. Ando, T. Ikeda, T. Kakutani, and $M$. Senda, Rev. Polarogr. (Kyoto), 26, 19 (1980).

15) T. Ikeda, S. Ando, and M. Senda, Bull. Chem. Soc. Jpn., 54, 2189 (1981).

16) G. Zanetti and A. Aliverti in Chemistry and Biochemistry of Flavoenzymes, Vol. II, ed. F. Muller, CRC press, Boston, 1991, pp.305.

17) P. A. Karplus, M. J. Daniels, and J. R. Herriot, Science, 251, 60, 1991. 